\title{
Erratum to: Temperature Effects on Deformation and Serration Behavior of High-Entropy Alloys (HEAs)
}

\author{
J. ANTONAGLIA, ${ }^{1} \mathrm{X} . \mathrm{XIE},{ }^{2} \mathrm{Z}$. TANG,${ }^{2}$ C.-W. TSAI ${ }^{3}$ J.W. QIAO, ${ }^{4}$ \\ Y. ZHANG ${ }^{5}$ M.O. LAKTIONOVA, ${ }^{6}$ E.D. TABACHNIKOVA, ${ }^{6}$ R. CARROLL, ${ }^{1}$ \\ J.W. YEH, ${ }^{3}$ O.N. SENKOV,${ }^{7}$ M.C. GAO,${ }^{8,9}$ J.T. UHL,${ }^{10}$ P.K. LIAW ${ }^{2}$ \\ and K.A. DAHMEN ${ }^{1,11}$ \\ 1.-Department of Physics, University of Illinois at Urbana Champaign, Urbana, IL 61801, USA. \\ 2.-Department of Materials Science and Engineering, The University of Tennessee, Knoxville, \\ TN 37996, USA. 3.-Department of Materials Science and Engineering, National Tsing Hua \\ University, Hsinchu 30013, Taiwan. 4.-College of Materials Science and Engineering, Taiyuan \\ University of Technology, Taiyuan 030024, People's Republic of China. 5.-State Key Laboratory \\ for Advanced Metals and Materials, University of Science and Technology Beijing, Beijing 100083, \\ People's Republic of China. 6.-B.I. Verkin Institute for Low Temperature Physics and Engi- \\ neering of National Academy of Sciences of Ukraine, Kharkiv 61103, Ukraine. 7.-Air Force \\ Research Laboratory, Materials and Manufacturing Directorate, Wright-Patterson Air Force \\ Base, OH 45433, USA. 8.-National Energy Technology Laboratory, Albany, OR 97321, USA. \\ 9.-USR Corporation, Albany, OR 97321, USA. 10.—Retired, USA. 11.—e-mail: dahmen@ \\ illinois.edu
}

\section{Erratum to: JOM, Vol. 66, No. 10, 2014 DOI 10.1007/s11837-014-1130-9}

R. Carroll was omitted from the originally published article. Author list and affiliations are correct as published here. 